\title{
IMPROVEMENT OF THERMAL ENERGY STORAGE BY INTEGRATING PCM INTO SOLAR SYSTEM
}

\author{
Mouna Ben Zohra ${ }^{1, *}$, Amine Riad $^{1 *}$, Abdelilah Alhamany ${ }^{1}$, Mohamed Sennoune $^{2}$, Mohamed Mansouri ${ }^{2}$
}

\begin{abstract}
The solar heater is a system that generates hot water by converting solar energy to thermal energy. In these last few years, various ways have been developed to gather this natural energy. However, they can not be able to store the energy when the sun disappears. In this study, thermal system based on phase change materials that improves the hot water production and stores thermal energy is proposed. In order to describe phase change materials and considers the effects of inclination angle on the production and storing thermal energy a numerical study has been carried out using the ANSYS-Fluent software. In addition, details concerning the choice of calculation range, mesh size, boundary conditions and turbulence model have been provided. The numerical results have been compared with previous data that was very promising.
\end{abstract}

\section{Keywords: Phase Change Materials, PCM, Solar Heater, Energy Storage, Energy Production, Thermal Energy}

\section{INTRODUCTION}

The solar energy is renewable and green resource; this energy can produce electricity from photovoltaic panels or heat from solar thermal collectors. As known, the production of domestic hot water in building consumes large amount of energy. For this reason, the solar energy appears, as an ideal solution using the solar heaters [1,2], which are systems that transform solar energy into thermal energy. These systems can produce a significant thermal energy that can satisfy the daily needs [3]. However, the solar system is at times at a loss or ineffective when the sun dissipates in the evening, when there are clouds or when the demand increases. For this reason, the solar heater needs an upgrade at the stage of producing and storing thermal energy. Therefore, there are several ways to manage the thermal energy among these methods, the production and storage of thermal energy by using phase change materials (PCMs) $[4,5]$. They are materials that can store solar energy as latent heat and become liquid by increasing the temperature. Later, heat is liberated when they are solidified. These materials are economical, ecological and efficient materials that can reduce energy consumption [6].

In order to upgrade the solar heater, various researches have been conducted. In this direction, Nayak and al. [7] established an experimental study that aims to face the dissimilarity in demand by storing thermal energy in tanks, still not enough to provide an effective backup. Besides, C. Wang [8] has carried out an experimental study that integrates phase change materials in reservoirs to improve thermal energy storage [9]. Additionally, the study conducted by Pagkalos and al. [10] supported the storage in integrated solar tank with PCM, which allows smaller tank to be used compared to larger traditional tank without reducing stored energy, which implies an advantage when space is taken into account. It has been confirmed that the development of thermal tanks plays a pivotal role in improving the exploitation of solar energy and storing it. Moreover, the use of PCM can increase the stored energy in tanks or benefits from smaller tanks where the space is considered. Therefore, diverse studies have been developed to expand the capacities of PCMs by investigating on engineering, type, and enclosure. Recently, Elfeky [11] found that to optimize thermal performance of the storage system, a multi-layered PCM is a necessary step for the best design and distribution of temperature. $\mathrm{Li}$ [12] found that to increase the flexibility of heat collection and supply, air-source heat pump should be used together with a thermal storage tank. When a PCM storage tank is used, the charging completion time and the total energy use are optimized. As a result, there is indispensable from use PCM to improve energy production and storage.

It can be concluded that is no escape from use PCM to step forward to enhance the storage and production of thermal energy in solar systems. Moreover, the previous studies analysed one side or mechanisms of the thermal system that utilize PCM in storage tank instead the PCM can be used in the collectors to increase collection of solar energy.

This paper was recommended for publication in revised form by Regional Editor N. Filiz Özdil

${ }^{1}$ MEET Laboratory, FST Settat, Hassan 1st University of Settat, Morocco

2 IMMII Laboratory, ENSA KHOURIBGA, Hassan 1st University of Settat, Morocco

*E-mail address: m.benzohra@uhp.ac.ma, am.riad@uhp.ac.ma

Orcid id: 0000-0002-3701-2641; 0000-0002-6526-8775

Manuscript Received 24 September 2018, Accepted 26 February 2019 
So, in order to increase thermal production and enhance thermal energy storage, a new solar heater that integrates phase change materials has been proposed. Moreover, a numerical study that describes the PCM behaviour in the solar collector has been conducted taking into account the effects of inclination angle on the production and storing thermal energy. Therefore, to verify the results accuracy, a numerical simulation using fluent ANSYS software was made.

\section{METHODOLOGY}

\section{- Thermal solar system model}

In this work, a numerical study aims to upgrade the solar system by integrating the phase change materials in the solar heater and in the tank that allows optimizing the production and the storage of thermal energy. The proposed solar system is based on the previous solar systems [13] that consist on solar heater and PCM tank as shown Figure 1:

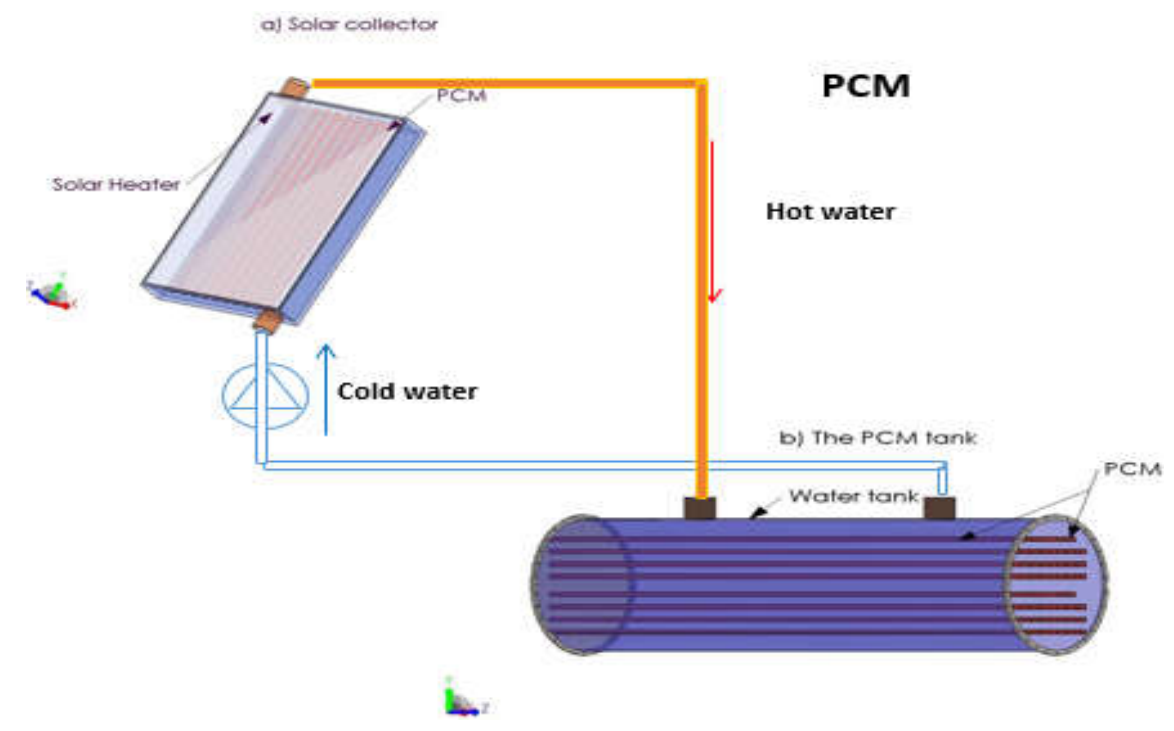

Figure 1. The proposed solar system based on PCM in solar collector and tank

The solar thermal systems provide a significant thermal energy from the sun that decrease the daily consummation of hot water and contribute greatly on energy economic. The heater depends mainly on two basic particles that we find in most devices of this type. It has been updated in this study by incorporating the PCM in the complex to improve and raise productivity and integrating the PCM in the tank to increase the storage capacity and the lack of storage space $[5,14,15]$. The proposed solar system (Figure 1) has:

$\checkmark$ The solar heater is a mechanism that can collect solar energy, which is converted into thermal energy that utilizes to heat a fluid, water or air. There are several types of solar heater, but in this study, the proposed solar heater has been chosen as a flat plate panel that has two main functions. The first one is the capture of thermal energy that comes from the sun; the second one is the storage of thermal energy using PCM that can speed up the next heating cycle.

$\checkmark$ The PCM tank [15,16] is an indispensable component that designed for the management of thermal energy in solar systems. Besides, the use of PCM of storing the heat and release it when needed or in the absence of the sun can improve the energy management.

The proposed solar system is designed to complete the previous solar systems, this upgrade is necessary to enhance solar heater by integrating PCM to improve thermal energy production and storage.

\section{- Physical model}

The PCM system in the solar system receives the heat from the sun by radiation and receive the heat from the solar heater by conduction and convection $[17,18]$. Indeed, the thermal energy collected is improved by taking into account the different heat transfers. It is supposed that the PCM system is homogeneous, isotropic, thermo-physical 
characteristics are constant, volume variation is negligible [19]. In that sense, we consider the system described in Figure 2.

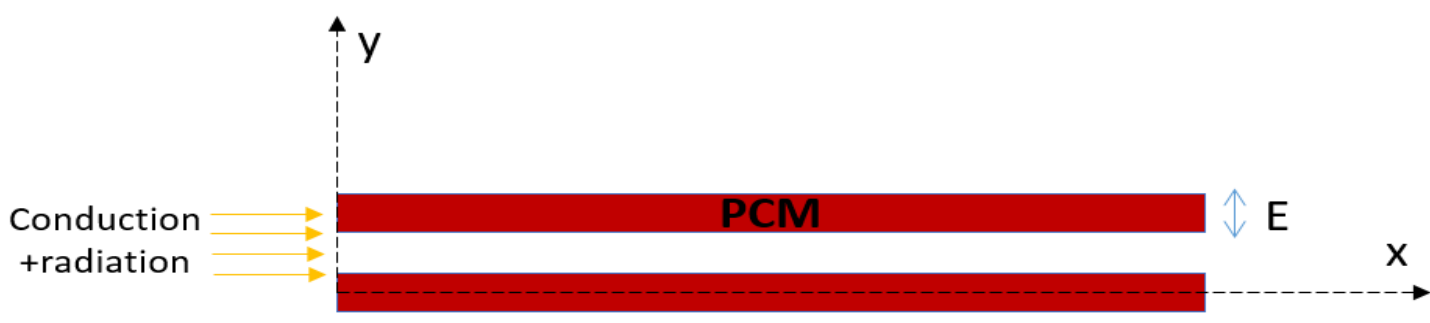

Figure 2. Diagram of simplified plates PCMs

The system in Figure 2 described the thermal energy storage in the PCM layers having thickness E, by the circulation of hot water [6]. Conversely, the circulation of cold water makes the destocking of thermal energy.

Table 1. Thermal properties of PCM

\begin{tabular}{|c|c|}
\hline $\mathrm{T}(\mathrm{x}, 0)=\mathrm{T}_{0}$ & PCM (RT64HC) \\
\hline Volume Mass & $\approx 820$ \\
$\left(\mathrm{Kg} / \mathrm{m}^{3}\right)$ & 1.9 (solid) \\
\hline Thermal Capacity & 2 (liquid) \\
$\left(\mathrm{KJ} / \mathrm{Kg} .{ }^{\circ} \mathrm{C}\right)$ & 0.2 (solid) \\
\hline Thermal Conductivity & 0.2 (liquid) \\
$\left(\mathrm{W} / \mathrm{m}^{\circ} \mathrm{C}\right)$ & 64 \\
\hline Fusion temperature & \\
$\left({ }^{\circ} \mathrm{C}\right)$ & 230 \\
\hline Latent heat & \\
$(\mathrm{KJ} / \mathrm{Kg})$ & \\
\hline
\end{tabular}

The PCM unit is rectangular plate [20] that is filled by paraffin with length $\mathrm{L}=25 \mathrm{~cm}$ and thickness $\mathrm{E}=6 \mathrm{~cm}$, (Figure 3).

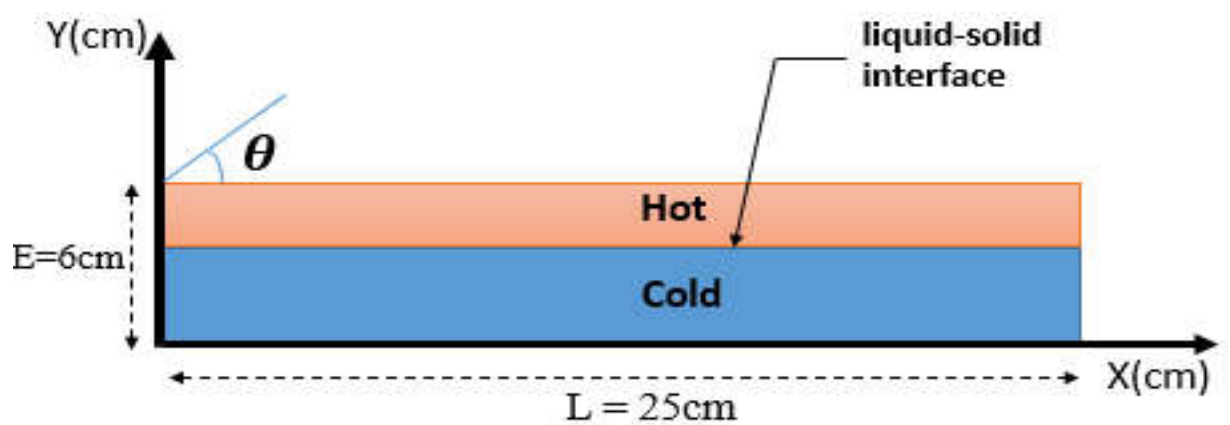

Figure 3. PCM proposed model design 


\section{NUMERICAL MODEL}

\section{- Governing equations}

In this study, the PCM was incorporated into the heating system in order to capture the largest amount of thermal energy, which will contribute to speeding up production and maintaining a large amount of thermal energy. Therefore, the solar system adopts the behaviour of the PCM, which can be explained by the governing equations. These equations describe the behaviour of The materials during the capture of energy and their explanation for storage during the change in the phase during fusion, the sum of the governing equations is three, which are the mass conservation equation, the momentum conservation equation and the energy conservation equation [21].

Under the assumption of laminar and incompressible flow, appealing the Boussinesq approximation in modelling the buoyancy force, the governing equations can be written as follows:

Mass conservation equation:

$$
\begin{gathered}
\vec{\nabla} \cdot \vec{V}=0 \\
\frac{\partial V x}{\partial x}+\frac{\partial V y}{\partial y}=0
\end{gathered}
$$

$\left(\mathrm{V}_{\mathrm{x}}, \mathrm{V}_{\mathrm{y}}\right)$ velocity components in $\mathrm{x}$ and $\mathrm{y}$ directions respectively.

Momentum conservation equation:

Projection on $\mathrm{x}$ :

$\rho\left(\frac{\partial V x}{\partial t}+V x \frac{\partial V x}{\partial x}+V y \frac{\partial V x}{\partial y}\right)=-\frac{\partial p}{\partial x}+\mu\left(\frac{\partial^{2} V x}{\partial x^{2}}+\frac{\partial^{2} V x}{\partial y^{2}}\right)-\rho g \beta\left(T-T_{0}\right) \sin \theta+\frac{\left(1-F_{l}\right)^{2}}{\left(F_{l}{ }^{3}-\varepsilon\right)} C m V x$

Projection on $\mathrm{y}$ :

$$
\rho\left(\frac{\partial V y}{\partial t}+V x \frac{\partial V y}{\partial x}+V y \frac{\partial V y}{\partial y}\right)=-\frac{\partial p}{\partial y}+\mu\left(\frac{\partial^{2} V y}{\partial x^{2}}+\frac{\partial^{2} V y}{\partial y^{2}}\right)-\rho g \beta\left(T-T_{O}\right) \cos \theta+\frac{\left(1-F_{l}\right)^{2}}{\left(F_{l}^{3}-\varepsilon\right)} C m V y
$$

With: $\mathrm{P}$ the pressure, $\rho$ the density, $\Theta$ angle of inclination, $\beta$ coefficient of thermal expansion, $\mu$ dynamic viscosity, $\mathrm{g}$ acceleration of gravity, $F_{l}$ liquid fraction, T: temperature, $T_{O}$ reference temperature .

Energy conservation equation:

$$
\frac{\partial(\rho h)}{\partial t}+V x \frac{\partial(\rho h)}{\partial x}+V y \frac{\partial(\rho h)}{\partial y}=K\left(\frac{\partial^{2} T}{\partial x^{2}}+\frac{\partial^{2} T}{\partial y^{2}}\right)
$$

With h: specific enthalpy and $K$ : thermal conductivity.

With $(\mathrm{Cm})$ the pasty zone that measures the velocity loss during phase transition. The zone speed is higher during fusion and it is lower during solidification.

The total enthalpy h can be described as the sum of sensible heat $S_{h}$ and latent heat $L_{h}$ that can be expressed:

$$
h=S_{h}+L_{h}=\int c_{p} d T+L F_{l}
$$

With $L:$ latent heat absorbed locally.

$\mathrm{C}_{\mathrm{p}}$ : specific heat . 


$$
F_{l}\left\{\begin{array}{lr}
0 & \left(T<T_{s l}\right) \\
\frac{T-T_{s l}}{T_{l q}-T_{s l}} & \left(T_{s l} \leq T \leq T_{l q}\right) \\
1 & \left(T>T_{l q}\right)
\end{array}\right.
$$

The eq. (5), using eq. (6) and eq. (7), rewrite as follows:

$$
\begin{gathered}
\frac{\partial\left[\left(\rho \int c_{p} d T\right)+L F_{l}\right]}{\partial t}+V x \frac{\partial\left[\left(\rho \int c_{p} d T\right)+L F_{l}\right]}{\partial x}+V y \frac{\partial\left[\left(\rho \int c_{p} d T\right)+L F_{l}\right]}{\partial y}=K\left(\frac{\partial^{2} T}{\partial x^{2}}+\frac{\partial^{2} T}{\partial y^{2}}\right) \\
\rho c_{p}\left(\frac{\partial T}{\partial t}+V x \frac{\partial T}{\partial x}+V y \frac{\partial T}{\partial y}\right)=K\left(\frac{\partial^{2} T}{\partial x^{2}}+\frac{\partial^{2} T}{\partial y^{2}}\right)-\rho L\left(\frac{\partial F_{l}}{\partial t}+V x \frac{\partial F_{l}}{\partial x}+V y \frac{\partial F_{l}}{\partial y}\right)
\end{gathered}
$$

\section{- Boundary \& initial conditions}

The boundary conditions and the gravity direction used for numerical simulation are depicted. At the top and the bottom surfaces, an adiabatic wall is defined. To avoid heat exchange between PCM and air, the interface domain is considered as a wall [22]. The adiabatic boundary condition stopped heating dissipation that is coming from the fluid heat transfer during the charging process. It is assumed that the top surface of the PCM plate receives hot temperature when the bottom one receives cold temperature. The boundary conditions are indicated in Figure 4 [23].

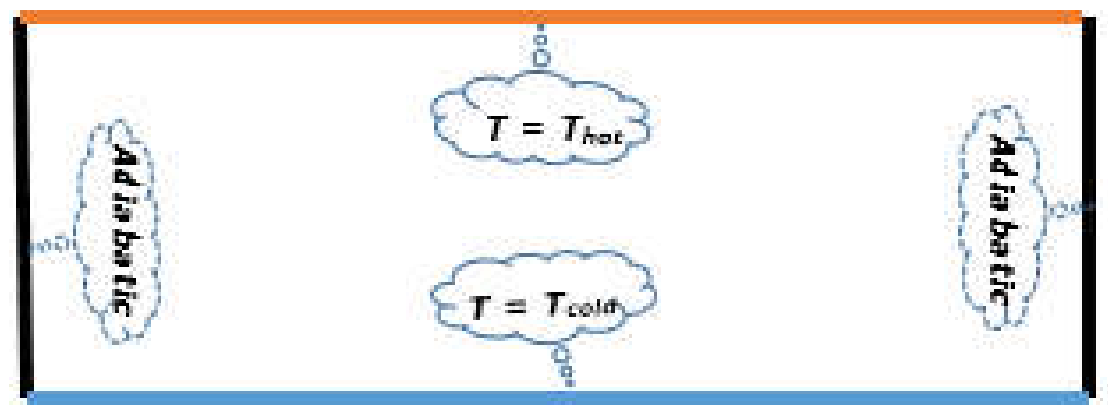

Figure 4. Indication of applied boundary conditions.

Table 2. Initial and boundary conditions

\begin{tabular}{|c|c|}
\hline $\mathrm{T}(\mathrm{x}, 0)=\mathrm{T} 0$ & Initial condition at $\mathrm{t}=0$ \\
\hline$\frac{\partial T(E, t)}{\partial x}=0$ & $\begin{array}{c}\text { Boundary condition at } \mathrm{x}=\mathrm{E} \\
\text { (the adiabatic boundary) }\end{array}$ \\
\hline$T(q(t), t)=T f$ & $\begin{array}{c}\text { Boundary condition at } \mathrm{x}=\mathrm{q}(\mathrm{t}) \\
\text { (melting front) }\end{array}$ \\
\hline$-K \frac{\partial T(0, t)}{\partial x}=w$ & $\begin{array}{c}\text { Boundary condition at } \mathrm{x}=0 \\
\text { (the boundary wich is subject } \\
\text { to constant heat flux } \mathrm{w})\end{array}$ \\
\hline
\end{tabular}




\section{RESULTS AND DISCUSSION}

In this work, the PCM was incorporated into the solar system that increase the amount of the captured heat. Consequently, the PCM optimize significantly thermal energy production and storage. Moreover, taking into account the optimal inclination angle allows the collector to collect more thermal energy.

Therefore, the PCM behaviour depends basically on the solar system that can influence the phase change, which can be explained by the governing equations. In this direction, a numerical study based on finite volume method using ANSYS FLUENT software has been conducted. Then, the accuracy of the study is verified by comparing numerical results with literature that show an excellent performance and good accordance [7,24] . Besides, the phase change material used for the numerical study is the paraffin that had a very high latent heat, obtainable and available on the market.

Assuming that $\mathrm{x}=0$ at the outer wall of the plate, the plate is initially at the $\mathrm{T}_{\mathrm{i}}=57^{\circ} \mathrm{C}$, the fluid temperature of the heat transfer $\mathrm{T}_{\infty}=69^{\circ} \mathrm{C}$. The phase change temperature of the paraffin $\mathrm{T}_{\mathrm{f}}=64^{\circ} \mathrm{C}$, the heat exchange coefficient [25]: $\mathrm{h}=220 \mathrm{~W} / \mathrm{m}^{2}{ }^{\circ} \mathrm{C}[26]$.

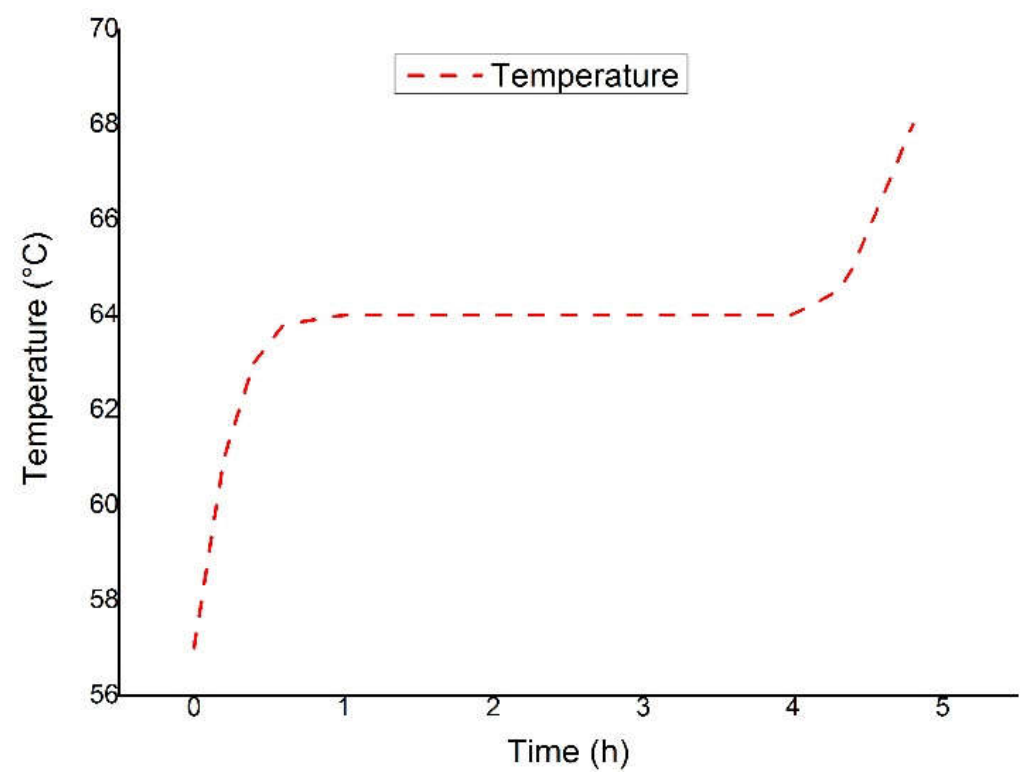

Figure 5. Evolution of the temperature of three points of the PCM

Figure 5 shows the evolution temperature as a function of time. The PCM is completely solid at $57^{\circ} \mathrm{C}$, then the melting begins after having absorbed all sensible heat between $57^{\circ} \mathrm{C}$ and $64^{\circ} \mathrm{C}$, next the material becomes completely liquid after $64^{\circ} \mathrm{C}$. Consequently, the paraffin melting process can be divided into three periods: The first is the time needed for the PCM to reach the melting temperature, the second is the time needed for the PCM to change phase and the third period is the time required for the PCM to reach the equilibrium temperature with the heat transfer fluid.

The obtained results show that PCMs absorb large amounts of heat, then the temperature increase till they reach the temperature of change phase (melting temperature), however, the PCM keeps absorbing heat until all material is converted to liquid phase. As a result, the simulation can describe the PCM behaviour [27]. Consequently, the enthalpy changes as a function of time, the system absorbed or released energy until the steady state is achieved, as shown in Figure 6. 

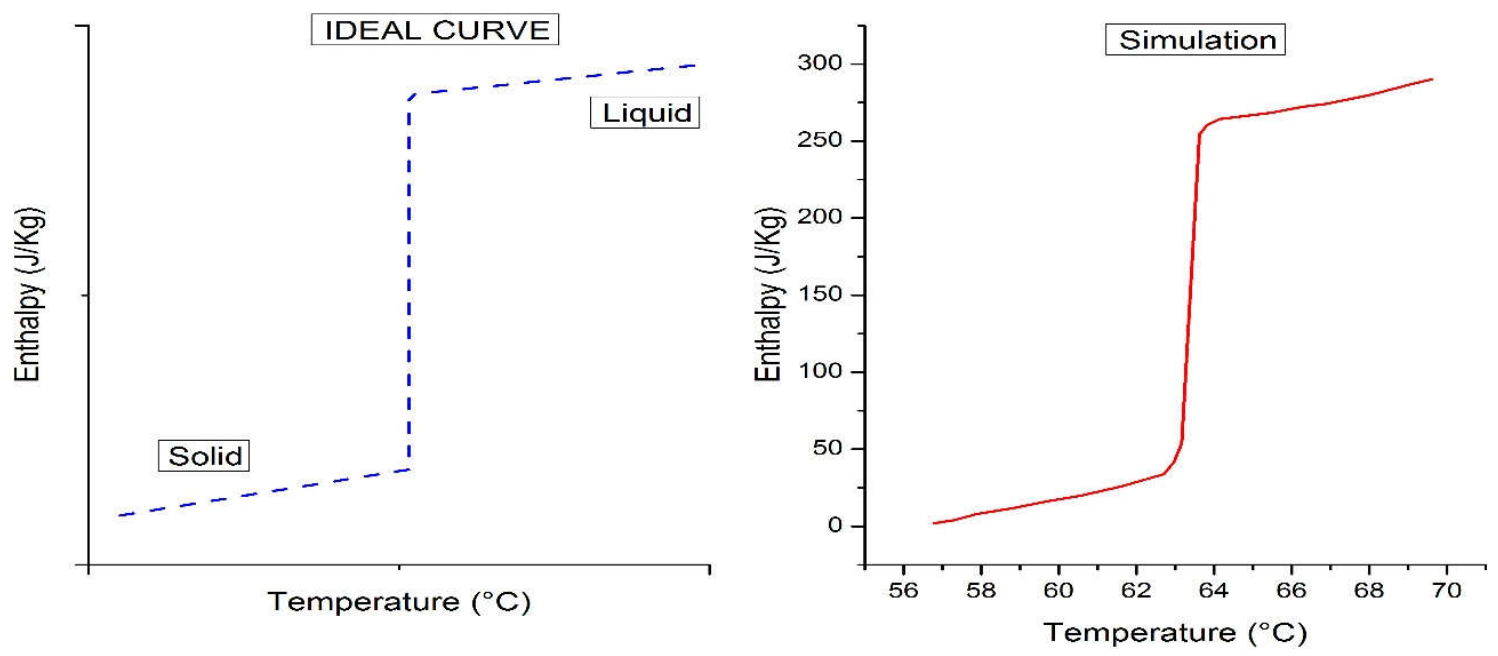

Figure 6. The evolution of enthalpy $h$ as a function of temperature

Figure 6 shows the enthalpy evolution $\mathrm{H}$ as a function of temperature. Hence, the slope of the enthalpy curves is very similar to those in the literature data (curve ideal). In the heating test, the enthalpy and the temperature are properly measured. The total enthalpy changes between $57^{\circ} \mathrm{C}$ and $69^{\circ} \mathrm{C}$ is $300 \mathrm{~J} / \mathrm{kg}$. In addition, the curve is decomposed into three parts during the heating test: Initially, the PCM stocks energy using sensible heat, then, the PCM change phase that the enthalpy increases quickly and the all the PCMs have the same temperature when the phase is changing. Then, the PCM stocks a large amount of heat using latent heat, in this case the PCM is completely liquid.

The amounts of energy using latent heat transfer involved in the phase change process are much larger than those involved in the sensible heat transfer. Now it is possible to reduce the storage volume and increase the energy stocked in the same storage volume.

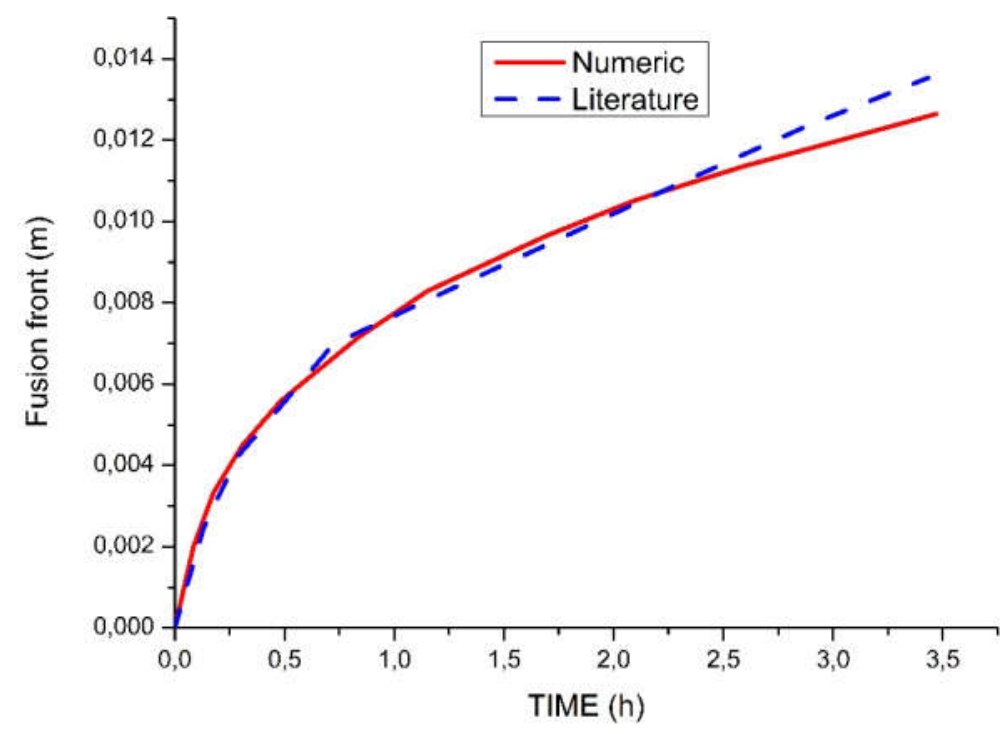

Figure 7. Evolution of the solid-liquid interface of the collector

In Figure 7, it is noticed that the fusion change as a function of time [26], when the temperature increases the fusion [28] also increases. Finally, it is deduced that the numerical and the experimental solutions of fusion displacement are in good agreement. 
The proposed geometry is a rectangular PCM plate. That has a height $\mathrm{H}$ and a thickness E. The simulation process depends on the mesh that an integral part which is influenced on the accuracy, convergence and speed of the simulation. Thus, the generated mesh is structured type that systematically meshed using symmetric squares which allows studying the PCM system during the melting-solidification process as shown in Figure 8:
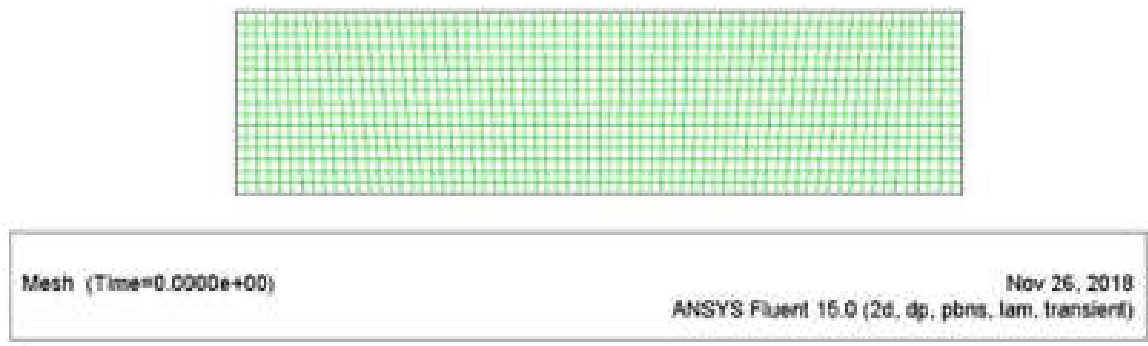

Figure 8. Geometry and mesh

The numerical study is conducted in ANSYS FLUENT software, that allows specifying various parameters associated with the solution method to be used in the calculation. The pressure-velocity coupling mode based on the SIMPLEC method. Besides, the pressure equation based on PRESTO method. The rest of the parameters are all defaults [29]. The convergence of study supervised by testing the numerically solved governing equations is reduced to less than $10^{-8}$ the number of iterations per time step is set to 100 and the time step is set at $1 \mathrm{~s}$. The simulation was performed on a $2 \mathrm{GHz}$ Intel Core i5 processor with $4 \mathrm{~GB}$ of RAM.

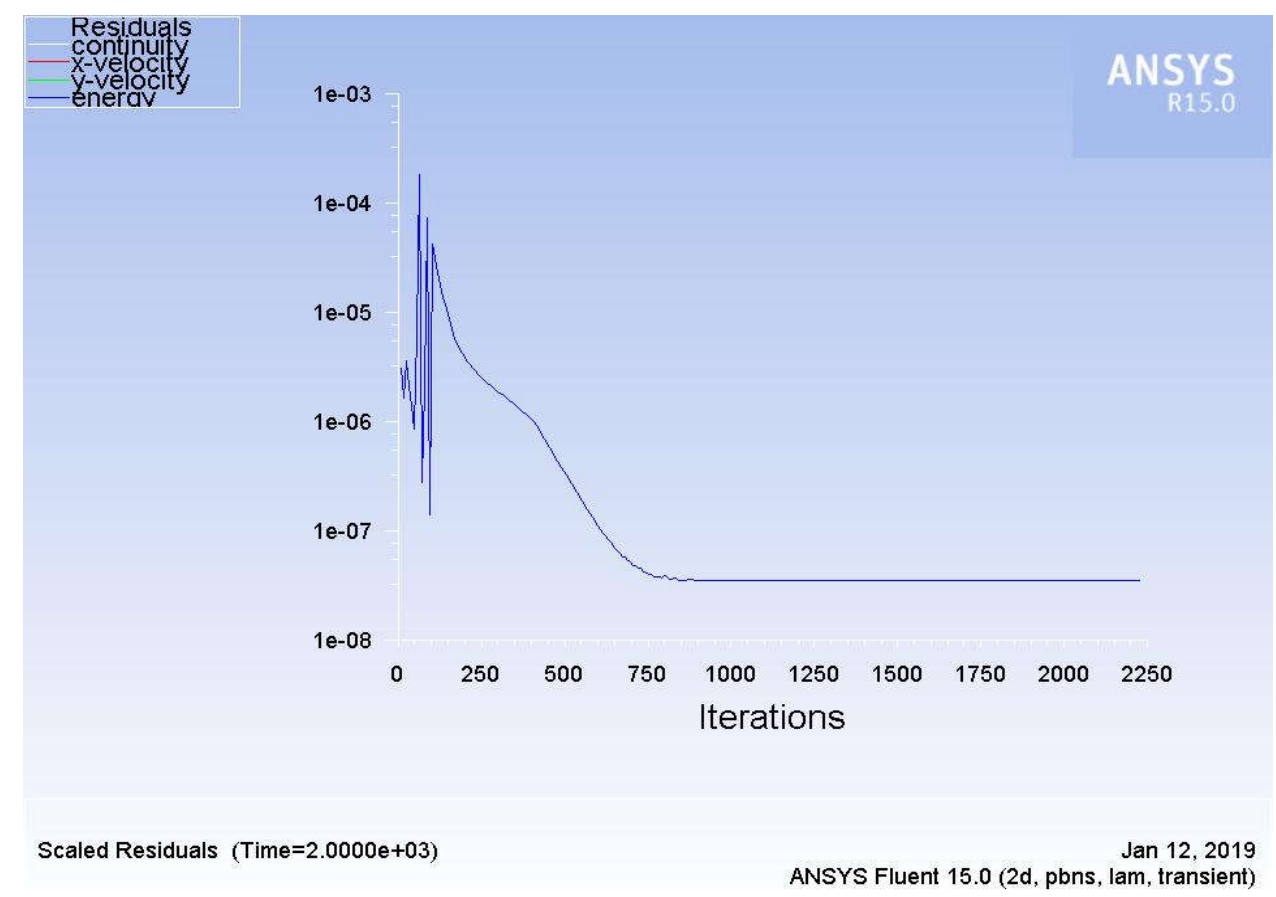

Figure 9. Convergence curve 

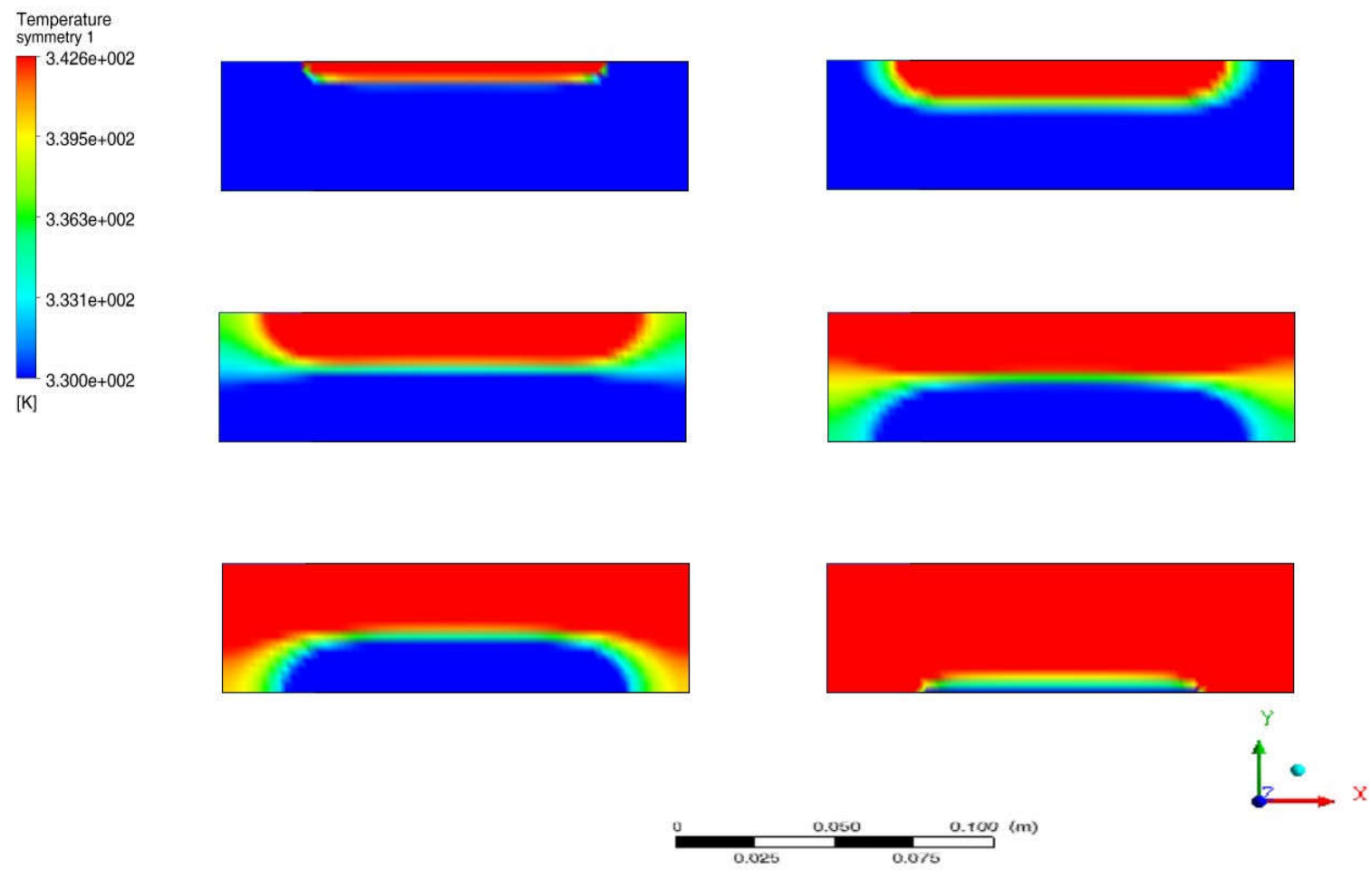

Figure 10. Temporal evolution of the PCM melting in the collector (from top to bottom) (30, 60, 90, 120, 150 and $240 \mathrm{~min})$

In the morning, the solar heater is cold as the PCM, then the sun face the solar heater and the system temperature increase. The PCM acquired the heat directly from the sun by radiation and indirectly from the solar heater by conduction. As the time passed to 10 minutes the PCM absorbed more heat is then used to phase change from solid state to a liquid state consequently the PCM begins the fusion procedure. Then, the fusion process is increased gradually due to the appearance of the natural convection in the liquid part of the PCM system. As a result, the conduction and the natural convection heat transfer are connected synchronously in the system. As the time passed to 90 minutes the fusion process increases significantly due to the raise of the natural convection that the half of the PCM is liquefied. The temperature of the system in the steady state condition when all of the PCMs are liquefied and heated to the inlet temperature. Comparing simulation results are in good concordance with the experiment results considering the aspect of total melting time and detail melting fractions [30].

It could be concluded that the numerical method valid results for the description of PCM phase change.

Obviously, employing PCMs in domestic hot water system allows improving the production of solar system compared to a system without PCM [31]. In that way, a comparison of the heat stored by three systems (without PCM, tank with PCM, both tank and collector with PCM) is done as shown in Figure 10:

The simulation result shown in Figure 11 reveals the advantages of the PCM existence in the proposed system. This is the reason why the system had a large amount of energy stored in the water tank and in the collector which can give stable heat compared with other systems, it is even more productive than a system without PCM or even better than a system with PCM in the tank [27]. In addition, the PCM can improve system performance and reduce power consumption, longer comparable to the system without PCM. 


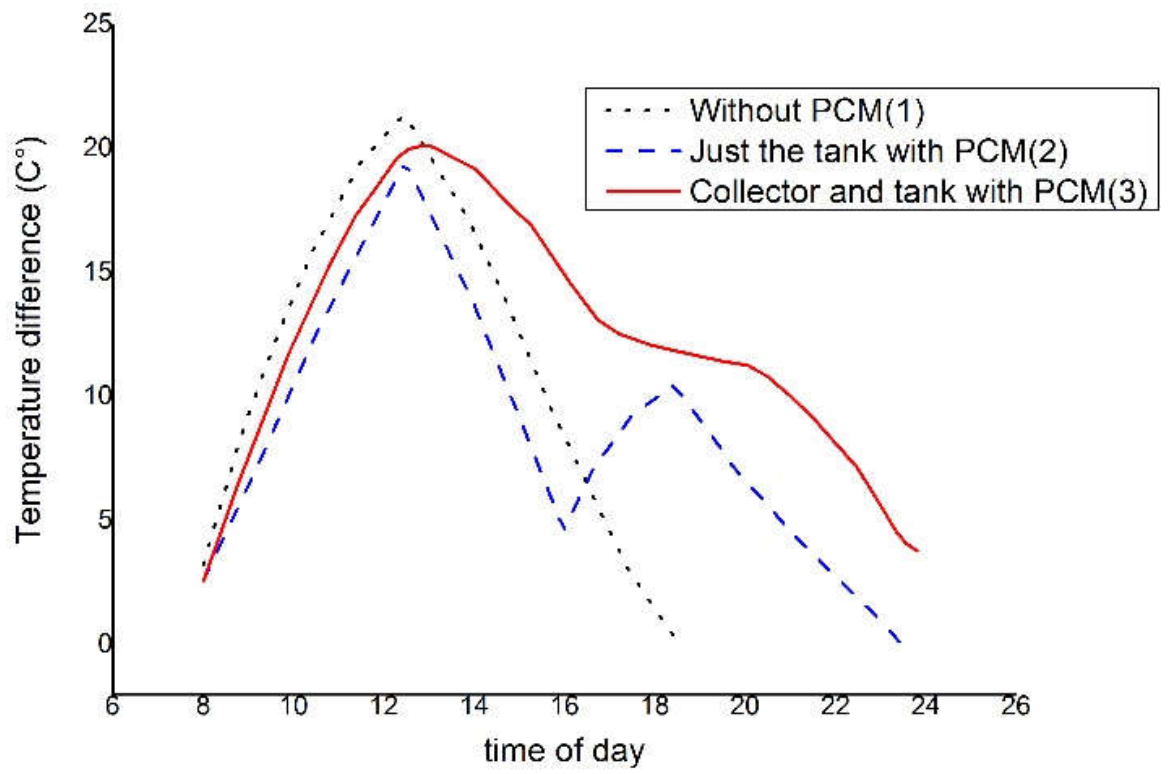

Figure 11. A comparison of the measured temperature difference of solar system with and without using PCM

To have a global understanding about the entire thermal process, it is proposed to analyse the tank, the amount of energy stored and the storage time. Therefore, a numerical study that compared the proposed system with PCM and the system without PCM [32], and described the heating and cooling process after $1000 \mathrm{~W}$ of thermal storage [33], as shown in Figure 12:

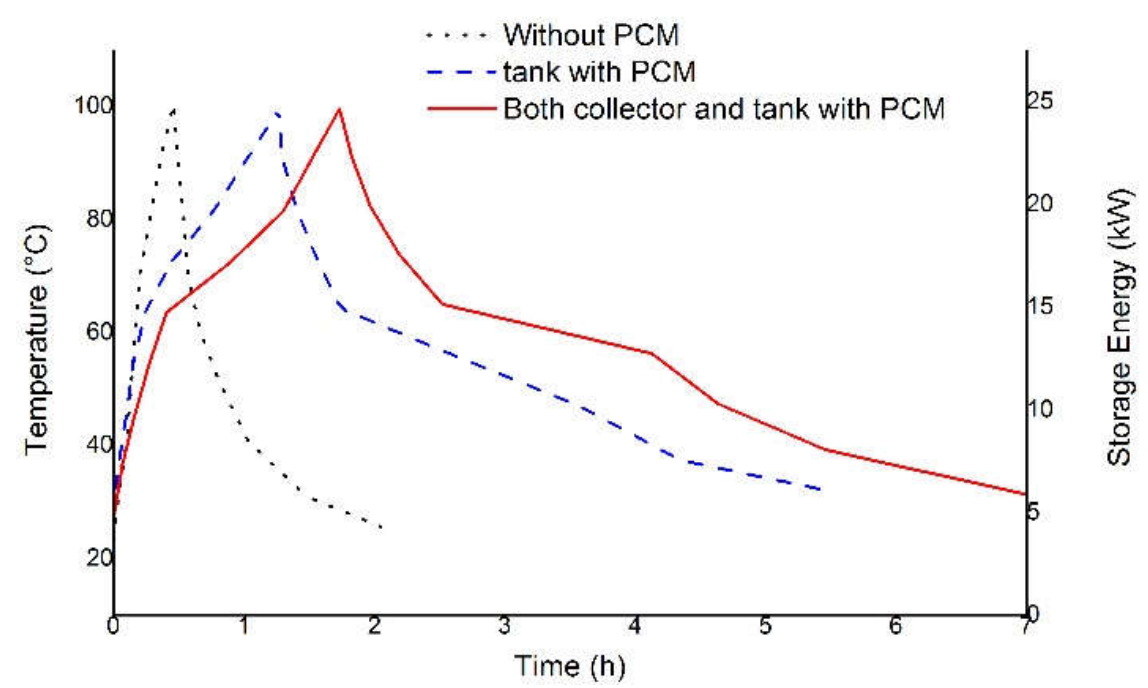

Figure 12. Storage of thermal energy dependence with time and temperature

It can be seen from Figure 12 that, the temperature of the solar system without PCM increases rapidly than the system with PCM, however, the stored energy in the proposed system is stable and more than the system without PCM just in tank and even more than the system without PCM. In this respect, the time needed for the discharge of the thermal energy stored is $1.74 \mathrm{~h}, 3.63 \mathrm{~h}$ and $4.55 \mathrm{~h}$ for the case without PCM, with PCM in the tank and with PCM in the tank and the collector, respectively [27]. 
The proposed system is able to store energy in the collector and in the tank, that the reason why the system without PCM realize the energy faster than the proposed system.

Therefore, the overall operation of the heating system can accelerate the heating, if the tank is exhausted, the collector heats the water quickly using the stocked energy in the PCM and using the energy comes from the sun.

In addition, the performance of the solar collector can be improved if the inclination angle effect is improved. For this reason, the inclination angle $\Theta$ varies from $0^{\circ}$ to $90^{\circ}$ then the liquid fraction evolution as a function of time [34] as shown in Figure 13 below:

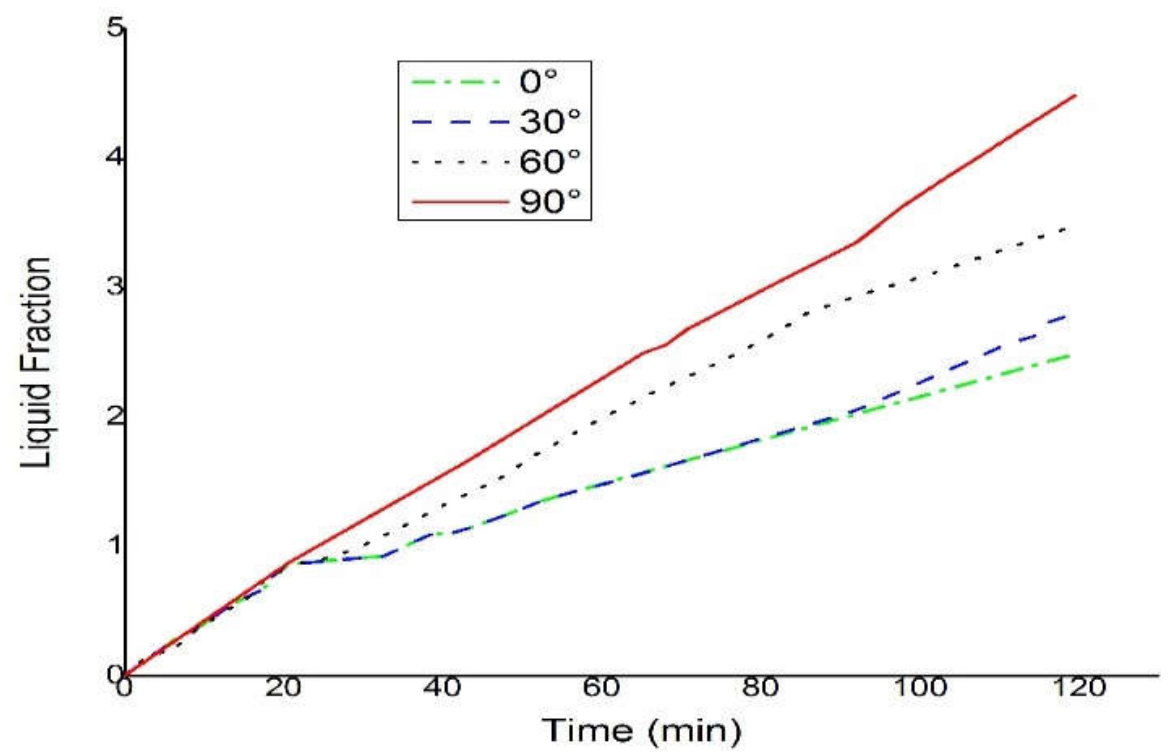

Figure 13. Evolution of the liquid fraction as a function of time for different values of $\Theta$

Figure 13 shows that the inclination of the PCM plate influences on the liquid fraction, when the inclination angle greater than $45^{\circ}$, the fraction liquid becomes large, contrary to the inclination less than $45^{\circ}$, it remains negligible.

The numerical results are significantly closer to the experimental solution during the process of paraffin loading and unloading. Therefore, a good agreement between proposed study results and experiment is obtained.

\section{CONCLUSION}

In this paper, a new design of the solar system has been proposed that incorporated the PCM into the heating system in order to capture the largest amount of thermal energy, which will contribute to accelerate production and maintaining a large amount of thermal energy. In this work, the PCM integrate into solar collector that have already two roles, from one side the system capture the heat from the sun by radiation and capture the heat from the solar heater by conduction. From the other side the system saves the acquired energy by phase change to accelerate heating.

The selected geometry is a rectangular plate that was modelled by the enthalpic method considering the boundary conditions of the proposed system and the obtained results are compared with the results in the literature. The obtained curves as a function of time are promising because they take a reasonable period for melting and the energy storage and therefore the next fusion-solidification cycles will be faster because the entourage temperature will be already increased. Therefore, the energy transfer will be faster. Hence, a simulation using ANSYS software has been conducted that adapted the PCM system to the solar system, which shows a good concordance with literature. To increase the effectiveness of this system, the angle of inclination is taken into account because the most the cavity is tilted, the more the melting accelerates and the melting rate increases. This system allows storing important quantities of energy in a short time compared to the other previous proposed systems with short periods. 
Journal of Thermal Engineering, Research Article, Vol. 6, No. 5, pp. 816-828, October, 2020

\section{REFERENCES}

[1] Kerme ED, Kaneesamkandi Zakariya. Performance Analysis and Design of Liquid Based Solar Heating System. J Therm Eng 2015;1:182-91. https://doi.org/10.18186/jte.02359.

[2] Yildirim C, Tümen Ö̈zdil NF. Theoretical investigation of a solar air heater roughened by ribs and grooves. J Therm Eng 2018;4:1702-12. https://doi.org/10.18186/journal-of-thermal-engineering.365713.

[3] Bhargav H, Ramani B, Siva Reddy V, Lai FC. Development of semi-continuous solar powered adsorption water chiller for food preservation. J Therm Eng 2018;4:2169-87. https://doi.org/10.18186/journal-of-thermalengineering.434032.

[4] Surana KS, Joy AD, Quiros LA, Reddy JN. Mathematical models and numerical solutions of liquid-solid and solid-liquid phase change. J Therm Eng 2015;1:61-98. https://doi.org/10.18186/jte.71504.

[5] Nourbakhsh A, Bayareh M. Study of the effect of the porous plates on the tank bottom on the boiling process. J Therm Eng 2019;5:149-56. https://doi.org/10.18186/thermal.540120.

[6] Reddy K, Mudgal V, Mallick T. Thermal Performance Analysis of Multi-Phase Change Material LayerIntegrated Building Roofs for Energy Efficiency in Built-Environment. Energies 2017;10:1367. https://doi.org/10.3390/en10091367.

[7] Nayak AO, Gowtham M, Vinod R, Ramkumar G. Analysis of PCM Material in Thermal Energy Storage System. Int J Environ Sci Dev 2011;01078:437-41. https://doi.org/10.7763/IJESD.2011.V2.165.

[8] Wang Z, Zhang H, Dou B, Zhang G, Wu W, Zhou L. An experimental study for the enhancement of stratification in heat-storage tank by equalizer and PCM module. J Energy Storage 2020;27:101010. https://doi.org/10.1016/j.est.2019.101010.

[9] Korti AIN. Numerical simulation on the effect of latent heat thermal energy storage unit. J Therm Eng 2016;2:599-607. https://doi.org/10.18186/jte.00934.

[10] Pagkalos C, Dogkas G, Koukou MK, Konstantaras J, Lymperis K, Vrachopoulos MG. Evaluation of water and paraffin PCM as storage media for use in thermal energy storage applications: A numerical approach. Int $\mathrm{J}$ Thermofluids 2020;1-2:100006. https://doi.org/10.1016/j.ijft.2019.100006.

[11] Elfeky KE, Li X, Ahmed N, Lu L, Wang Q. Optimization of thermal performance in thermocline tank thermal energy storage system with the multilayered PCM(s) for CSP tower plants. Appl Energy 2019;243:175-90. https://doi.org/10.1016/j.apenergy.2019.03.182.

[12] Li Y, Zhang N, Ding Z. Investigation on the energy performance of using air-source heat pump to charge PCM storage tank. J Energy Storage 2020;28:101270. https://doi.org/10.1016/j.est.2020.101270.

[13] Elbahjaoui R, El Quarnia H. Optimisation D’Une Unite De Stockage D’Energie Solaire Par Chaleur Latente De Fusion Utilisant La Cire De Paraffine (Praffin Wax P116 ). 12ème Congrès de Mécanique 2015;21-24 Avri:1-3.

[14] Ünal F, Temir G, Köten H. Energy, exergy and exergoeconomic analysis of solar-assisted vertical ground source heat pump system for heating season. J Mech Sci Technol 2018;32:3929-42. https://doi.org/10.1007/s12206-018-0744-1.

[15] Zhao J, Ji Y, Yuan Y, Zhang Z, Lu J. Energy-Saving Analysis of Solar Heating System with PCM Storage Tank. Energies 2018;11:237. https://doi.org/10.3390/en11010237.

[16] Beemkumar N, Karthikeyan A, Keshava Reddy KS, Rajesh K, Anderson A. Analysis of Thermal Energy Storage Tank by ANSYS and Comparison with Experimental Results to Improve its Thermal Efficiency. IOP Conf Ser Mater Sci Eng 2017;197. https://doi.org/10.1088/1757-899X/197/1/012039.

[17] Yilbas BS, Siddiqui OK. Volumetric solar absorber and performance characteristics. J Therm Eng 2015;1:1528. https://doi.org/10.18186/jte.09757.

[18] Bondareva NS, Sheremet MA. Numerical simulation of natural convection melting in 2D and 3D enclosures. J Therm Eng 2019;5:51-61. https://doi.org/10.18186/thermal.513015.

[19] Mohammed MAP, Tarleton E, Charalambides MN, Williams JG. Mechanical characterization and micromechanical modeling of bread dough. J Rheol (N $\mathrm{Y}$ N $\mathrm{Y}$ ) 2013;57:249-72. https://doi.org/10.1122/1.4768463.

[20] Chan CW, Tan FL. Solidification inside a sphere - An experimental study. Int Commun Heat Mass Transf 2006;33:335-41. https://doi.org/10.1016/j.icheatmasstransfer.2005.10.010.

[21] Ben Zohra M, Riad A, Alhamany A, Sennoune M. Coupled thermo-fluidic model for thermal energy storage based on liquid solid phase change. Mater Res Express 2020;7:0-12. https://doi.org/10.1088/2053$1591 / \mathrm{ab} 73 \mathrm{fc}$.

[22] Tian Y, Zhao C-Y. Heat transfer analysis for phase change materials (PCMs) 2009:1-8.

[23] Petrone G. CL and CG. Numerical simulation of pcm melting process 2012:469-74.

[24] Koller M, Walter H, Hameter M. Transient numerical simulation of the melting and solidification behavior of 
Journal of Thermal Engineering, Research Article, Vol. 6, No. 5, pp. 816-828, October, 2020

NaNo3using awire matrix for enhancing the heat transfer. Energies 2016;9. https://doi.org/10.3390/en9030205.

[25] Vlachopoulos J, Strutt D. Basic Heat Transfer and some applications ind polymer processing. Plast Tech Toolbox 2002;2:21-33.

[26] Benbrika M, Benbelhout M, Teggar M. Amélioration de 1' efficacité thermique d 'un chauffe -eau solaire par 1 ' utilisation de matériaux à changement de phase ( MCP ). Int J Sci Res Eng Technol 2015; Vol.4 pp.1.

[27] Saw CL, Al-Kayiem HH, Owolabi AL. Experimental investigation on the effect of PCM and Nano-enhanced PCM of integrated solar collector performance. WIT Trans Ecol Environ 2013;179 VOLUME:899-909. https://doi.org/10.2495/SC130762.

[28] Younsi Z, Joulin A, Zalewski L, Rousse D. Analyse Numérique De La Fusion De Matériaux À Changement De Phase Dans Une Enceinte. IXème Colloq Interuniv Fr Sur La Therm Des Systèmes 2009.

[29] Augspurger M, Udaykumar HS. A Cartesian grid solver for simulation of a phase-change material (PCM) solar thermal storage device. Numer Heat Transf Part B Fundam 2016;69:179-96. https://doi.org/10.1080/10407790.2015.1097106.

[30] Yadav A, Soni S. Simulation of Melting Process of a Phase Change Material (PCM) using ANSYS (Fluent). Int Res J Eng Technol 2017:2395-56.

[31] Yang XH, Tan SC, He ZZ, Liu J. Finned heat pipe assisted low melting point metal PCM heat sink against extremely high power thermal shock. Energy Convers Manag 2018;160:467-76. https://doi.org/10.1016/j.enconman.2018.01.056.

[32] Ponshanmugakumar A, Scholar R, Madhan R, Narayanan AL, Rajavel R. Thermal Energy analysis using TRNSYS in PCM Storage Tank. Int J Futur Revolut Comput Sci Commun Eng n.d.:1-5.

[33] Ezan MA, Ozdogan M, Gunerhan H, Erek A, Hepbasli A. Energetic and exergetic analysis and assessment of a thermal energy storage (TES) unit for building applications. Energy Build 2010;42:1896-901. https://doi.org/10.1016/j.enbuild.2010.05.025.

[34] Joneidi MH, Hosseini MJ, Ranjbar AA, Bahrampoury R. Experimental investigation of phase change in a cavity for varying heat flux and inclination angles. Exp Therm Fluid Sci 2017;88:594-607. https://doi.org/10.1016/j.expthermflusci.2017.07.017. 